\title{
Investigation of olfactory function in a Panx1 knock out mouse model
}

\author{
Stefan Kurtenbach ${ }^{1 *}$, Paige Whyte-Fagundes ${ }^{1}$, Lian Gelis ${ }^{2}$, Sarah Kurtenbach ${ }^{1}$, Émerson Brazil ${ }^{1}$, \\ Christiane Zoidl' ${ }^{1}$, Hanns Hatt ${ }^{2}$, Valery I. Shestopalov ${ }^{3,4}$ and Georg Zoidl ${ }^{1}$ \\ ${ }^{1}$ Department of Psychology, Faculty of Health, York University, Toronto, ON, Canada \\ ${ }^{2}$ Department of Cell Physiology, Ruhr University Bochum, Bochum, Germany \\ ${ }^{3}$ Department of Ophthalmology, Bascom Palmer Eye Institute, Miller School of Medicine, University of Miami, Miami, FL, USA \\ ${ }^{4}$ Vavilov Institute of General Genetics, Russian Academy of Sciences, Moscow, Russia
}

\section{Edited by:}

Juan Andrés Orellana, Pontificia

Universidad Católica de Chile, Chile

Reviewed by:

Christian Giaume, Collège de

France, France

Juan Andrés Orellana, Pontificia

Universidad Católica de Chile, Chile

*Correspondence:

Stefan Kurtenbach, Department of

Physiology, Faculty of Health, York

University, 4700 Keele Street,

Toronto, ON M3J 1P3, Canada

e-mail: stefan.kurtenbach@me.com
Pannexin 1 (Panx1), the most extensively investigated member of a channel-forming protein family, is able to form pores conducting molecules up to $1.5 \mathrm{kDa}$, like ATP, upon activation. In the olfactory epithelium (OE), ATP modulates olfactory responsiveness and plays a role in proliferation and differentiation of olfactory sensory neurons (OSNs). This process continuously takes place in the $\mathrm{OE}$, as neurons are replaced throughout the whole lifespan. The recent discovery of Panx 1 expression in the OE raises the question whether Panx 1 mediates ATP release responsible for modulating chemosensory function. In this study, we analyzed pannexin expression in the OE and a possible role of Panx 1 in olfactory function using a Panx $1^{-/-}$mouse line with a global ablation of Panx1. This mouse model has been previously used to investigate Panx 1 functions in the retina and adult hippocampus. Here, qPCR, in-situ hybridization, and immunohistochemistry (IHC) demonstrated that Panx1 is expressed in axon bundles deriving from sensory neurons of the $\mathrm{OE}$. The localization, distribution, and expression of major olfactory signal transduction proteins were not significantly altered in Panx $1^{-/-}$mice. Further, functional analysis of Pan $\times 1^{-/-}$animals does not reveal any major impairment in odor perception, indicated by electroolfactogram (EOG) measurements and behavioral testing. However, ATP release evoked by potassium gluconate application was reduced in Pan $\times 1^{-/-}$mice. This result is consistent with previous reports on ATP release in isolated erythrocytes and spinal or lumbar cord preparations from Pan $\times 1^{-/-}$mice, suggesting that Pan $\times 1$ is one of several alternative pathways to release ATP in the olfactory system.

Keywords: pannexin, Panx1, olfaction, knock out mouse, extracellular ATP, electroolfactogram, behavior

\section{INTRODUCTION}

Genomes of higher vertebrates contain three pannexin genes (Panx1, Panx2, and Panx3) that share homologies with invertebrate gap junction proteins named innexins (Baranova et al., 2004) and membrane topologies similar to vertebrate connexins, a novel class of integral membrane glycoproteins. Unlike connexins, pannexins function as unopposed channels (Sosinsky et al., 2011) that open through various stimuli like activation of purinergic receptors and high intracellular calcium (Locovei et al., 2006), cellular stretch (Bao et al., 2004), high extracellular potassium levels (Silverman et al., 2009), and depolarization (Bruzzone et al., 2003; Pelegrin and Surprenant, 2006). Pannexins are known to be expressed in sensory systems like the cochlea (Wang et al., 2009), retina (Dvoriantchikova et al., 2006; Zoidl et al., 2008), taste buds (Huang et al., 2007), and olfactory epithelium (OE) (Zhang et al., 2012).

Panx1 has moved into the focus of purinome research due to the ability to form large channel pores capable of conducting big molecules like ATP. The presence of pannexins in different chemosensory systems raises the general question of whether they may contribute to sensory perception by releasing ATP and modulating purinergic signaling. Perception of sensory stimuli also involves purinergic signaling at various levels: ATP can influence cochlear function through multiple mechanisms, including modulation of hearing sensitivity, sound transduction, neurotransmission, and even influencing gap-junctional coupling (Bobbin and Thompson, 1978; Muñoz et al., 1995; Zhu and Zhao, 2012). ATP release plays a primary role in signal transmission of taste cells to afferent nerve fibers (Finger et al., 2005) and a similar mechanism seems to hold true for keratinocytes (Azorin et al., 2011). In the retina, purinergic signals act as neuro- and gliotransmitters, most likely modulating retinal responses on various levels (Prochnow et al., 2009; Wurm et al., 2011; Vessey and Fletcher, 2012). In the OE, extracellular ATP elicits increases in $\left[\mathrm{Ca}^{2+}\right]_{\mathrm{i}}$ in both olfactory sensory neurons (OSNs) and sustentacular cells (SCs), leading to a suppression in odor responsiveness (Hegg et al., 2003). ATP also evokes inward currents and increased $\left[\mathrm{Ca}^{2+}\right]_{\mathrm{i}}$ in sensory neurons in the vomeronasal organ (VNO), by activation of $\mathrm{P} 2 \mathrm{X}$ receptors (Vick and Delay, 2012). 
The introduction of several Panxl knock out animal models, with distinct genetic ablation strategies (Bargiotas et al., 2011, 2012; Dvoriantchikova et al., 2012; Hanstein et al., 2013), has initiated ample opportunities to investigate Panx1 functions from genes through to systems and behavioral outcomes. Since sensory inputs to the CNS can be altered in $\mathrm{Panx}^{-/-}$mice, as shown recently for the retina (Kranz et al., 2013; Vroman et al., 2014), it was hypothesized that similar changes could be found in other sensory organs. In this study, we characterize the impact of genetic ablation of Panx1 in the olfactory system. Expression and localization studies demonstrated Panx1 expression in the OE. Surprisingly, Panx1 was mainly localized in OE axon bundles and not at the apical surface of the cilia, where the olfactory receptors are present and the olfactory signal transduction cascade is initiated. The OE of Panx1 $1^{+/+}$and Panx1 $1^{-/-}$mice showed no altered response to odors in electroolfactogram (EOG) measurements, suggesting that Panxl is dispensable for acute olfactory function. However, a quantitative comparison of extracellular ATP concentration revealed significant differences between the two genotypes after exposure to potassium gluconate. Further, behavioral outcomes revealed small, but significant abnormalities in the processing of olfactory information, accompanied by a higher mobility of Panx $1^{-/-}$mice. Our data do not support a prominent role of Panx1 channels in olfaction, and it was concluded that the behavioral abnormalities observed in Panx $1^{-/-}$mice derive from alterations of integrating neuronal processes, as observed in the hippocampus. However, our data suggest that Panx1 is one of several alternative pathways to release ATP in the olfactory system and that dissecting these pathways will be a critical step to define the exact role(s) of Panxl in sensory systems.

\section{METHODS}

\section{Panx1 KNOCKOUT MICE}

Panx $1^{+/+}$mice $($Panx1fl/fl) with three LoxP consensus sequences integrated into the Panxl gene and knockout mice with global loss of Panx1 (Panx1-/-, CMV-Cre/Panx1) were described previously (Gründken et al., 2011; Dvoriantchikova et al., 2012; Prochnow et al., 2012). Handling and housing of animals used in this study was performed in compliance with the German Animal Rights law and approved by the Landesamt für Natur, Umwelt und Verbraucherschutz Nordrhein-Westfalen, Germany (Permission No. 50.8735.1 Nr. 100/4) and formal approval by the Animal Care Committee (York University, Canada). Adult male mice (4-8 months of age) were housed individually 1 week prior to, and during, behavior testing.

\section{IN-SITU HYBRIDIZATION (ISH)}

Digoxigenin (dig)-labeled sense and antisense cRNA probes were prepared from a full length Panxl cloned into the pcDNA3 plasmid as described previously (Ray et al., 2006). After linearization of the plasmid, sense and antisense cRNA probes were transcribed using T7 and SP6 RNA polymerase with dig-RNA labeling mix (Roche, Germany). The ISH was performed as described (Larsson et al., 2004) with minor modifications. OE from P7 mice were dissected and immediately embedded in tissue freezing medium (Leica, Germany) at $-30^{\circ} \mathrm{C}$ and cryostat sections $(12 \mu \mathrm{m})$ were cut immediately. Slides were subsequently fixed in $4 \%$ paraformaldehyde in $\mathrm{PBS}$ at $4^{\circ} \mathrm{C}$ for $20 \mathrm{~min}$, washed in
PBS and acetylated by a 15 min treatment in $0.1 \mathrm{M}$ triethanolaminhydrochloride solution with $0.25 \%$ acetic anhydride on a stir plate. Sections were rinsed in $2 \times \mathrm{SSC}(30 \mathrm{mM} \mathrm{NaCl}$ and $3 \mathrm{mM}$ sodium citrate) and prehybridized in hybridization buffer $(50 \%$ formamide, $5 \times$ SSC, $5 \times$ Denhardts' solution, $2.5 \mathrm{mM}$ EDTA, $50 \mu \mathrm{g} / \mathrm{ml}$ heparin, $250 \mu \mathrm{g} / \mathrm{ml}$ tRNA, $500 \mu \mathrm{g} / \mathrm{ml}$ salmon sperm DNA, and $0.1 \%$ Tween-20) for $1 \mathrm{~h}$ at $55^{\circ} \mathrm{C}$. Riboprobes were added to the hybridization buffer ( $50 \mathrm{ng}$ in $200 \mu$ l hybridization buffer), denaturized at $80^{\circ} \mathrm{C}$ for $2 \mathrm{~min}$ and applied to sections. Sections were incubated over night at $55^{\circ} \mathrm{C}$ for hybridization. Post-hybridization, slides were washed with $0.2 \times$ SSC for $1 \mathrm{~h}$ and then with $0.1 \times$ SSC for $15 \mathrm{~min}$, to remove non-specific binding. Sections were subsequently equilibrated for $10 \mathrm{~min}$ in PBS containing $0.1 \%$ TritonX-100 (PBST), blocked with $10 \%$ goat serum in PBST buffer for $1 \mathrm{~h}$, and then incubated with 1:1000 alkaline phosphatase (AP) conjugated anti-dig Fab fragment (Roche, Germany) in blocking solution overnight $(\mathrm{ON})$ at $4^{\circ} \mathrm{C}$. Finally, slides were washed in PBST, equilibrated in B3-Buffer (0.1 Tris$\mathrm{HCl}, 0.1 \mathrm{M} \mathrm{NaCl}, 50 \mathrm{mM} \mathrm{MgCl} 2,0.1 \%$ Tween-20), followed by treatment with NBT/BCIP (Roche, Germany) $(20 \mu \mathrm{l} / \mathrm{ml} \mathrm{B3})$ to visualize the hybridized probes.

\section{IMMUNOHISTOCHEMISTRY (IHC)}

After the fur and palate were removed, heads from adult male mice were fixed in $4 \%$ PFA at $4^{\circ} \mathrm{C} \mathrm{ON}$, then immersed in $30 \%$ sucrose at $4^{\circ} \mathrm{C}$ ON. $12 \mu \mathrm{m}$ cryosections were prepared, blocked with $5 \%$ cold-water fish skin gelatine for $1 \mathrm{~h}$ at RT, and primary antibodies (1:250, Santa Cruz, CA, G $\alpha$ olf sc-383; CNG sc-13700, ACIII sc-588, acetylated tubulin sc-23950) were applied in $1 \%$ cold-water fish skin gelatin in PBS containing $0.1 \%$ Triton X-100, at $4^{\circ} \mathrm{C}$ ON. After $30 \mathrm{~min}$ washing in PBS, secondary goat antirabbit antibodies Alexa Fluor 568 (Invitrogen, Germany) were applied for $30 \mathrm{~min}$ at RT in PBS. After $30 \mathrm{~min}$ washing in PBS, sections were embedded in ProlongGold Antifade (Invitrogen, Germany).

The Laird laboratory generously provided an antibody for Panx1 IHC (Penuela et al., 2007). For Panx1 detection the following modifications were introduced. For antigen retrieval, fixed cryostat sections were incubated for 5 min with $1 \%$ SDS, followed by three washes for $5 \mathrm{~min}$ with PBS. After blocking for $1 \mathrm{~h}$ at RT with $5 \%$ normal goat serum (NGS), $1 \%$ bovine serum albumin (BSA), and $0.1 \%$ Triton X100 in PBS, the primary antibody was diluted (1:100) in 1\% BSA, $0.1 \%$ Triton $\mathrm{X} 100$ in PBS. After ON incubation, specimen were washed three times with PBS for $10 \mathrm{~min}$ each. The secondary goat anti-rabbit Alexa Fluor 488 antibody was diluted (1:1000) in PBS and applied for $30 \mathrm{~min}$ at RT, followed by three washes for $10 \mathrm{~min}$ with PBS.

Confocal microscopy was performed using a ZEISS LSM700 microscope. ZEISS ZEN software was used to control all parameters during imaging. Identical settings were used to allow a direct comparison of IHCs of Panx1 $1^{+/+}$and $\mathrm{Panx}^{-/-}$mice. LSM images were exported into tiff format and assembled using Photoshop CS.

\section{qPCR}

RNA was isolated from adult male mice using the RNAeasy Fibrous Tissue Mini Kit (Invitrogen, Canada) and cDNA 
was synthesized from $1 \mu \mathrm{g}$ total RNA with the ReadyScript cDNA Synthesis Kit (Sigma-Aldrich, Canada), according to the manufacturer's instructions. qPCR was performed using the SsoFast EvaGreen Supremix (Bio-Rad, Canada) and the following oligonucleotide pairs: Panxlfw: CAGGCTGCCTTTGTGGATTC Panxlrev: CGGGCAGG TACAGGAGTATG Panx2fw: GGTACCAAGAAGGCCAAGA CT Panx2rev: GGGGTACGGGATTTCCTTCTC Panx3fw: CTTA CAACCGTTCCATCCGC Panx3rev: CAGGTACCGCTCTAGC AAGG 18Sfw: TGACTCTTTCGAGGCCCTGTA 18Srev: TGGA ATTACCGCGGCTGCTG. fw, forward; rev, reverse. Experiments were performed in triplicates, using three biological replicates. Relative gene expression was calculated using the REST software (2009) (Pfaffl et al., 2002). 18S served as the reference gene.

\section{EOG RECORDINGS}

Skulls from adult male mice were cut parasagittal to the septum to expose the nasal cavity. The turbinates were removed and EOGs were recorded from the OE on the septum. A constant, deodorized, humidified air stream was delivered to the OE and adjusted to $2.4 \mathrm{l} / \mathrm{min}$. Henkel 100 (H100, Henkel, Germany), a mixture of 100 different odors (Wetzel et al., 1999), was used as a stimulus. Dilutions were made in distilled water and soaked into a piece of felt, which was placed into a custom-made injection device. Recording electrodes were made from pulled glass capillaries containing chloride silver wires and filled with Ringer's solution ( $140 \mathrm{mM} \mathrm{NaCl}, 5 \mathrm{mM} \mathrm{KCl}, 1 \mathrm{mM} \mathrm{CaCl}_{2}, 1 \mathrm{mM}$ $\mathrm{MgCl}_{2}, 10 \mathrm{mM}$ HEPES, $\mathrm{pH}$ 7.4). During recording, heads were placed on $2 \%$ agarose dissolved in Ringer's solution containing the reference electrode. Student's $t$-test was used for statistical analysis.

\section{EX VIVO ATP ASSAY}

The intact $\mathrm{OE}$ was exposed after skulls from adult male mice were cut parasagittal to the septum to expose the nasal cavity. Once the OE was entirely exposed, the tissue was positioned in upside down orientation. Since the OE rapidly degenerates once axons get transsected, this ex vivo preparation was used instead of more invasive dissection procedures to extract extracellular ATP from the cilia surface. To avoid mechanical stimulation small droplets $(25 \mu \mathrm{l})$ of Ringers solution, H100 [Henkel 100, 1:10000 in Ringers solution, Henkel, Germany (Wetzel et al., 1999)], and potassium gluconate (25 mM, Sigma-Aldrich, diluted in Ringers solution) were subsequently and gently pipetted onto the cilia surface at the center of the OE. The tissue was incubated for the indicated timespans. Between steps droplets were fully removed. Solutions contained $100 \mu \mathrm{M}$ ARL 67156 trisodium salt hydrate (Sigma-Aldrich) to inhibit ATPases. Samples were heated at $95^{\circ} \mathrm{C}$ for $1 \mathrm{~min}$ after extraction, flash frozen, and stored at $-80^{\circ} \mathrm{C}$ until used. ATP assays were performed in 96 well format; using the Molecular Probes ${ }^{\circledR}$ ATP Determination Kit (Life Technologies, USA) and the Synergy H4 hybrid multiwell plate reader (Biotek, USA). ATP concentrations were determined from ATP standard curves included in each assay. To test for statistical significance the student's $T$-test was used.

\section{BEHAVIORAL TESTS Cookie-finding test}

To familiarize the mice with the experimental setup, adult male mice were trained for 1 day to find a cookie ( $1 \mathrm{~g}$ ) (Leibniz Butterkeks; Bahlsen, Germany) buried beneath $6 \mathrm{~cm}$ of woodchip bedding in their home cage. On the following days, smaller cookies of defined weight were hidden (see Results). The time to locate the cookie was determined from video recordings. We defined finding the cookie as the time point when mice held it in both fore paws. If a mouse did not find the cookie within $15 \mathrm{~min}$, the test was aborted and most of the bedding above the cookie was removed, enabling the mouse to find the cookie very easily (usually within $1 \mathrm{~min}$ ). Cookie-finding tests were analyzed using the $U$-test due to data truncation.

\section{Mobility analysis}

Animal mobility was analyzed with the EthoVision XT7 Software from Noldus (Wageningen, Netherland). Mobility was defined as distance per time. Tracking was stopped when the animal found the cookie. To test for statistical significance, Student's $T$-test was used.

\section{RESULTS}

\section{PANNEXIN EXPRESSION AND LOCALIZATION IN THE OLFACTORY EPITHELIUM}

Pannexin expression was determined in the mouse OE and whole brain lysate using qPCR and primer pairs specific for Panx1 (GI:86262133). Panx1 mRNA expression was found in the brain and $\mathrm{OE}$ adult mice (Figure 1), with mean cycle threshold $\left(\mathrm{C}_{t}\right)$ values of $29.8 \pm 0.5$ (brain) and $31.3 \pm 0.9$ (OE). Panx2 was expressed in the $\mathrm{OE}$ at significantly lower expression levels compared to the brain $(p<0.001)$. Mean cycle threshold $\left(C_{t}\right)$ values were $27.2 \pm 0.7$ (brain) and 33.9 \pm 0.7 (OE). No Panx3 expression was detected $\left(C_{\mathrm{t}}<35\right)$. Neither in the brain, nor in the OE a compensatory upregulation of Panx 2 or Panx 3 mRNA was observed in $\mathrm{Panx}^{-/-}$mice. Consistent with the genetic phenotype, no Panx1 mRNA expression $\left(C_{\mathrm{t}}<35\right)$ was found in Panx1 ${ }^{-/-}$animals lacking exons 3 and 4 (Dvoriantchikova et al., 2012).

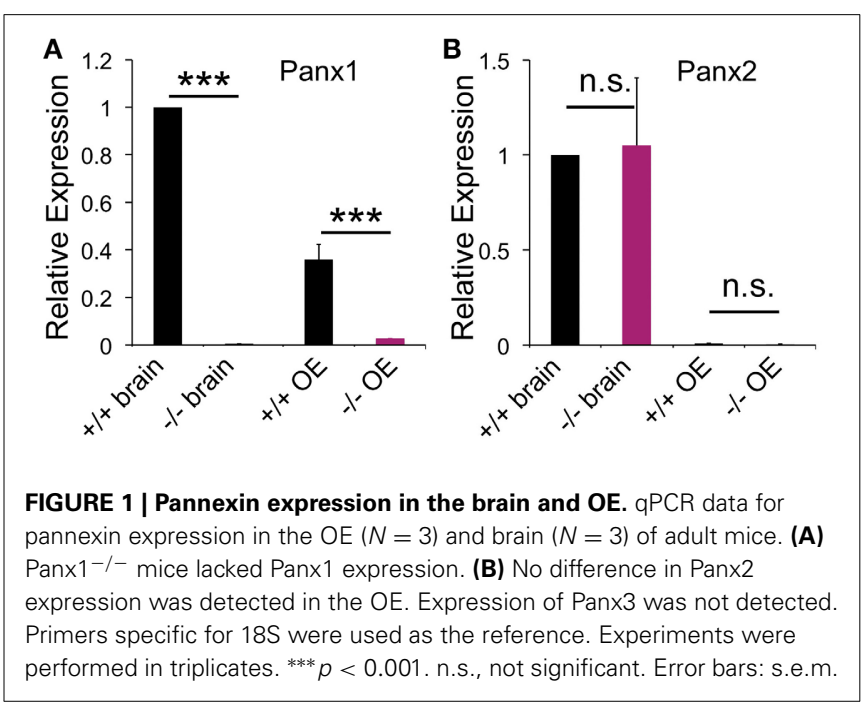


Localization of Panx1 expression sites in the OE were determined using in-situ hybridization technology and cRNA probes specific for mouse Panx1 (Ray et al., 2006). Figure 2 shows a representative distribution of Panx1 mRNAs in the OE. The sense cRNA probes generated only a very weak background staining, demonstrating the antisense probes' specificity. In the $\mathrm{OE}$, a strong staining of the OSN layer and a less intense staining of the sustentacular (SC, arrows) and basal cell (BC) layers were observed.

To validate mRNA localization data, immunohistochemistry (IHC) was performed using an antibody specific for mouse Panx1 (Penuela et al., 2007). In Panx $1^{+/+}$animals (Figure 3), the IHC of the OE revealed a significant labeling of the OSN axon bundles, projecting to the olfactory bulb. Virtually no staining was found in OSN axon bundles of Panx $1^{-/-}$mice. However, a diffuse signal was observed in the basal-, neuronal-, and SC layers. No pronounced staining was found in OSN cilia, which inherit olfactory receptor proteins and signaling proteins involved in OSN signaling/depolarization after odorant activation.

\section{ODORANT DETECTION IS NOT ALTERED IN Panx1-/- MICE}

When an olfactory receptor (OR) is activated, the signal transduction cascade elicited through the OR typically evokes a massive influx of calcium mediated by cyclic nucleotide gated (CNG) channels. Since Panxl channels can be activated by raised intracellular calcium levels (Locovei et al., 2006), we investigated whether the lack of Panxl alters the response of the OE upon odor application by performing electroolfactogram (EOG) measurements in adult male mice. A mixture of 100 different odorants [Henkel 100 (H100) (Wetzel et al., 1999)] was applied via a constant, humidified airstream to activate a broad range of ORs. Figure 4A shows a typical response amplitude after odorant

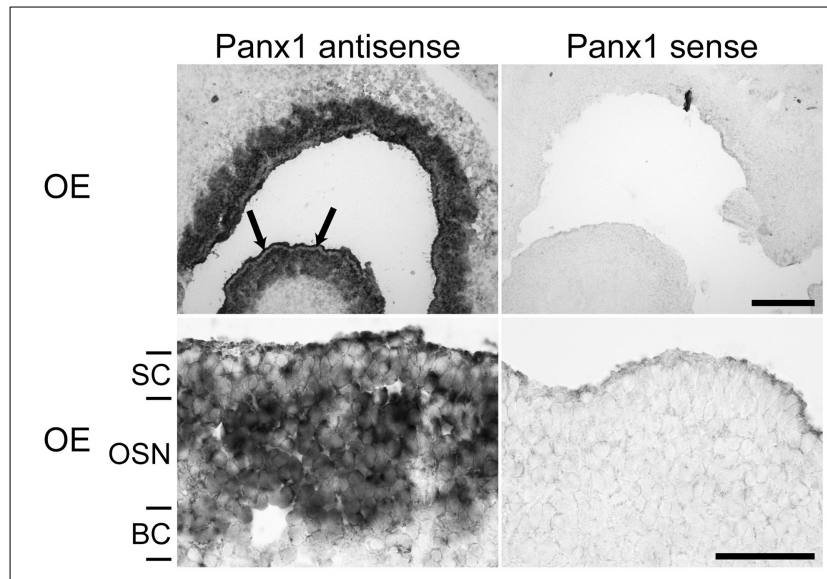

FIGURE 2 | In-situ hybridizations with riboprobes specific for Panx1. In-situ hybridizations from juvenile mice (P7) with Panx1 riboprobes. Panx1 antisense probes delivered strong labeling in the OE. Strong staining in the OE was present in the OSN layer. Weaker staining of SCs was more obvious in the overview (upper left, indicated by arrows). The BC layer showed weaker staining than the OSN layer. Scale bars $=200 \mu \mathrm{m}$, and $100 \mu \mathrm{m}$ (close-up, middle) (OE, olfactory epithelium; SC, sustentacular cells; OSN, olfactory sensory neuron; BC, basal cell layer). application for $100 \mathrm{~ms}$. Results were quantified and summarized in Figure 4B. No significant difference in the response amplitudes for Panx $1^{+/+}(N=7)$ and Panx1 $1^{-/-}(N=8)$ mice were detected (minimum 10 measurements on different locations per mouse, $\operatorname{Panx} 1^{+/+}=4.2 \pm 0.2 \mathrm{mV}, \mathrm{Panx}^{-/-}=4.7 \pm$ $0.3 \mathrm{mV}, p=0.17)$. Further, the response kinetics, namely the rise time $\left(\mathrm{Panx}^{+/+}=86 \pm 3 \mathrm{~ms}\right.$, Panx $1^{-/-}=94 \pm 4 \mathrm{~ms}, p=0.1$ ) and decay time $\left(\mathrm{Panx}^{+/+}=989 \pm 191 \mathrm{~ms}, \mathrm{Panx}^{-/-}=984 \pm\right.$ $128 \mathrm{~ms}, p=0.98)$, did not differ between both animal groups.
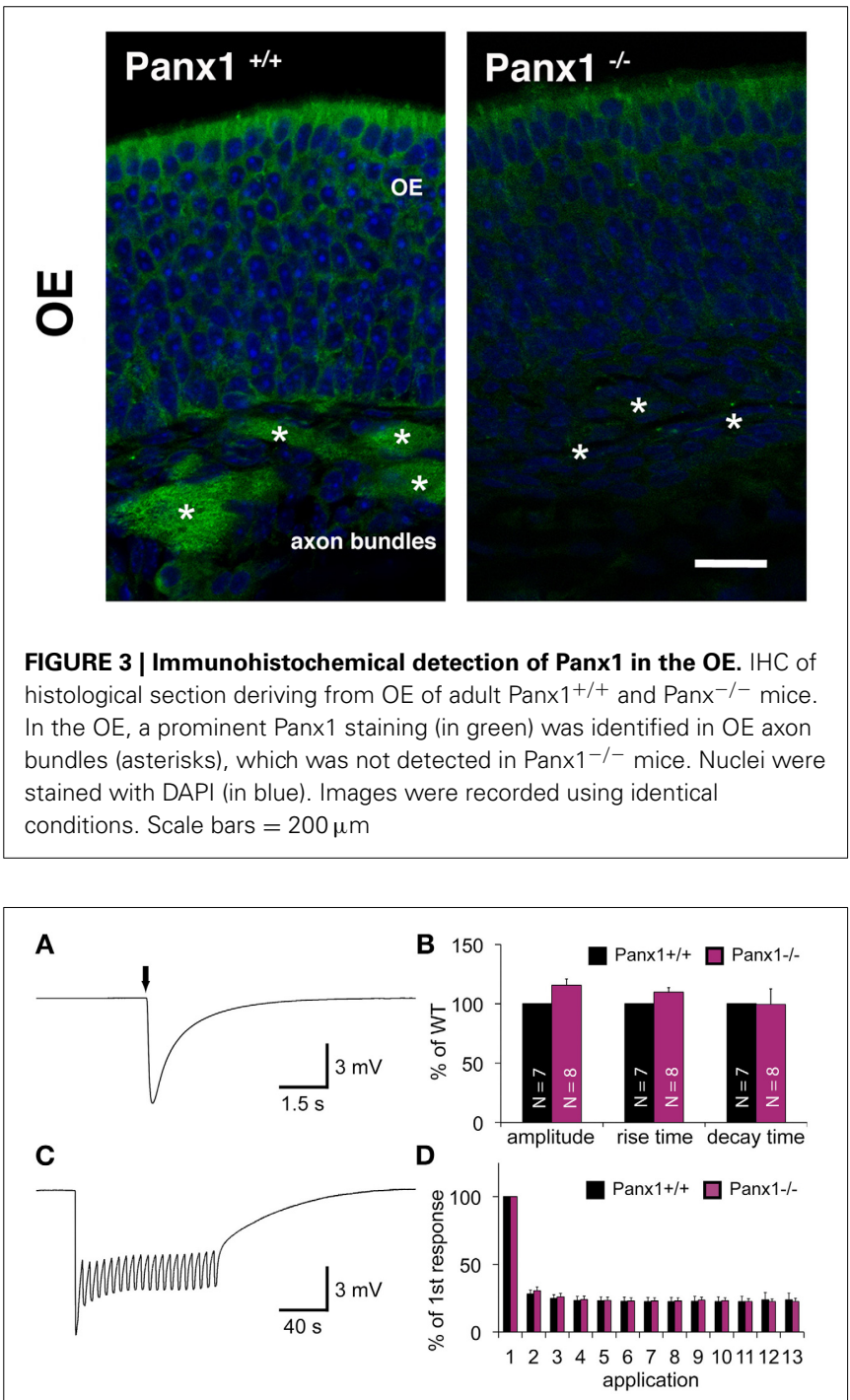

FIGURE 4 | EOG recordings of Panx $1^{+/+}$and Panx $1^{-/-}$olfactory epithelium. (A) Sample EOG response after application of a single odorant pulse (100 ms; 1:1000 H100). (B) Quantification of single odorant pulses. Amplitude and response kinetics [rise (10-90\%) and decay (90-10\%) time] are not significantly different in Panx $1^{-/-}$mice $(p>0.05)$. Data were normalized to Panx $1^{+/+}$values. $\mathrm{N}_{\mathrm{Pan} \times 1^{+/+}}=7 ; \mathrm{N}_{\mathrm{Pan} \times 1^{-/-}}=8$; minimum 10 measurements per mouse. (C) Sample recording of multiple odor applications (1 s; 4 s interstimulus interval; 1:1000 H100). (D) Quantification of 13 adaptation measurements (depicted in $\mathbf{C}$ ). Responses ( $\Delta$ of individual responses) were normalized to the first response. No significant differences were found ( $\mathrm{N}_{\text {Panx } 1+/+}=6 ; \mathrm{N}_{\text {Panx1-/- }}=6 ; 1$ measurement per mouse). Error bars indicate s.e.m. (EOG, electroolfactogram; H100, Henkel 100). 
To test the ability of the OE to adapt to odorants, we measured odor responses after a repetitive stimulation paradigm (Brunert et al., 2009) $\left(\mathrm{N}_{\mathrm{Panx}^{+/+}}=6, \mathrm{~N}_{\mathrm{Panx}^{-/-}}=6,1 \mathrm{~s}\right.$ stimulus duration, $4 \mathrm{~s}$ interstimulus interval, 1 measurement per mouse), as depicted in Figures 4C,D. Using this paradigm, we achieved a robust adaptation to less than $30 \%$ of the control level, but adaptation kinetics observed in Panx $1^{-/-}$animals were statistically insignificant to those in wild type mice. Since Panx $1^{+/+}$and Panx $1^{-/-}$responded equally to both experimental conditions, we concluded that loss of Panxl did not alter physiological odorant responses. Further confirming this finding, ablation of Panx1 did not cause a significant change in the localization and distribution of the four major olfactory signal transduction proteins detecting adenylyl cyclase 3 (ADCYIII), cyclic nucleotide gated channel alpha 2 (CNGA2), olfactory neuron specific-G protein $\left(G_{\text {olf }}\right.$ ), and acetylated tubulin (AcTub) (Supplementary Figure 1). Similarly, quantification of the mRNA expression of adenylyl cyclase 3 (ADCYIII), cyclic nucleotide gated channel alpha 2 (CNGA2), and olfactory neuron specific- $G$ protein $\left(G_{\text {olf }}\right)$ using qPCR revealed no difference (Supplementary Figure 2).

\section{ATP RELEASE IN THE OE OF Panx1-/- MICE}

Panxl is considered to be a major ATP release channel in various tissues. We quantified extracellular ATP using ex vivo preparations of the OE (Figure 5). During this procedure the OE is placed upside down for extracellular ATP extraction. Due to the small size of the OE, ATP was extracted in a $25 \mu \mathrm{l}$ droplet of Ringers solution gently placed at the center of the OE. After equilibration for $3 \mathrm{~min}$, droplets recovered from the Panx $1^{+/+}$ and Panx1-/-OEs had an ATP concentration in the $\mathrm{pM}$ range. Extracellular ATP concentrations in the $25 \mu \mathrm{l}$ droplet increased more than 100 fold when this extraction step was repeated with Ringers solution containing the ATPase inhibitor (ARL 67156). No significant difference was detected $(p=0.66)$, suggesting that ablation of Panxl did not compromise efflux of extracellular ATP. After Ringers solution with ATPase inhibitor was completely removed, the odorant mixture Henkel 100 was applied for $90 \mathrm{~s}$ in a small droplet $(25 \mu \mathrm{l})$ placed again at the center of the OE. No significant differences in extracellular ATP release in both mouse strains were detectable. The concentration of extractable ATP was slightly reduced to the previous step reflecting the reduced extraction time. It was concluded that alternative ATP release pathways primarily promoted the observed ATP efflux in response to the odorant. Subsequently $25 \mathrm{mM}$ potassium gluconate in Ringers solution $(25 \mu \mathrm{l})$ was applied for $90 \mathrm{~s}$. Significant differences in extracellular ATP levels were detected $\left(\mathrm{Panx}^{+/+}, 3.4 \pm 0.4 \mathrm{pM}\right.$; Panx $1^{-/-} 2.2 \pm 0.3 \mathrm{pM} ; p=0.022$ ), suggesting that Panx1 channels contributed significantly to ATP release in this experimental condition.

\section{ODORANT PERCEPTION IN Panx1-/- MICE}

The results shown suggested that loss of Panxl does not impair detection of odorants in the OE. However, Panx1 is expressed in other cells of the olfactory system, including subsets of neurons in the olfactory bulb and the piriform cortex (Bruzzone et al., 2003; Ray et al., 2005). To test for odorant perception, a cookie-finding test was performed. In this behavioral test, an odorous cookie was

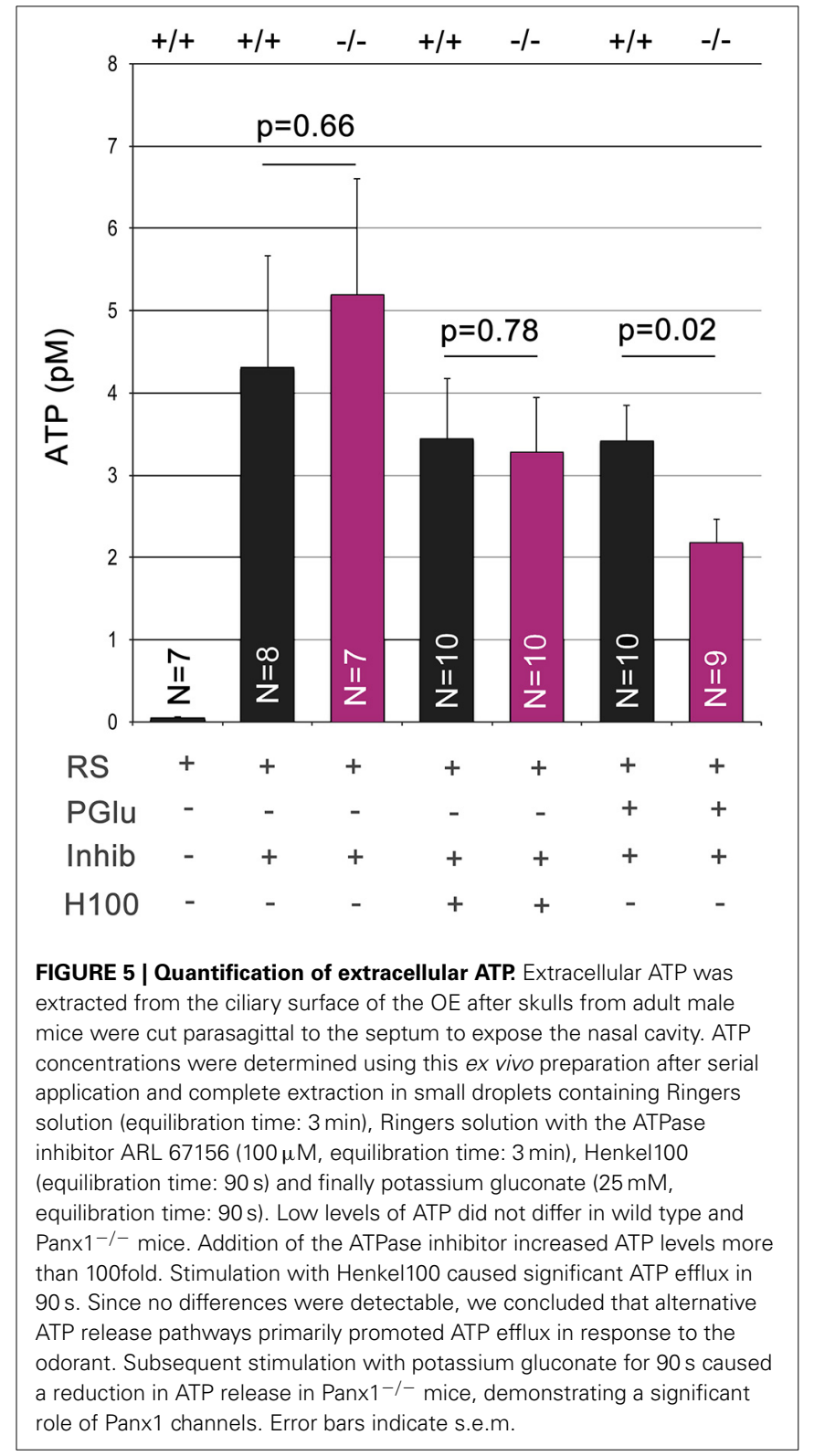

hidden beneath the bedding in the home cage of each mouse and the latency until the mice found the treat was determined. Tests were conducted on four subsequent days (Figure 6A). On the training day $(\mathrm{T})$, a large cookie $(1 \mathrm{~g})$ was hidden. The size (and odor) allowed the mice to familiarize with the test. Panx $1^{+/+}$ $(N=15)$ and Panx1 ${ }^{-/-}(N=14)$ mice performed equally on test day 1 , when test conditions were more difficult for the mice ( $50 \mathrm{mg}$ cookie; Panx $\left.1^{+/+}=627 \pm 83 \mathrm{~s}, \mathrm{Panx}^{-/-}=630 \pm 82 \mathrm{~s}\right)$. We performed two more tests using a large [150 mg (day 2)] and a small $[50 \mathrm{mg}$ (day 3$)]$ cookie. On day 2 , Panx $1^{+/+}$animals showed a tendency to find the cookie faster than $\mathrm{Panx}^{-/-}$mice, however, this difference was not significant $\left(\mathrm{Panx}^{+/+}=212 \pm\right.$ $\left.83 \mathrm{~s}, \mathrm{Panx}^{-/-}=428 \pm 82 \mathrm{~s}, p=0.1\right)$. When the difficulty of the test was increased on day 3 (50 mg cookie), Panx1 $1^{-/-}$mice took significantly longer to find the cookie $\left(\mathrm{Panx}^{+/+}=149 \pm\right.$ 


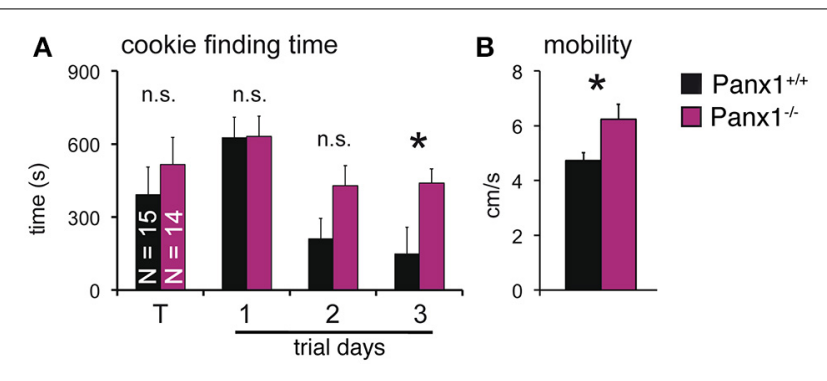

FIGURE 6 | Cookie-finding test. (A) Latency to find a hidden cookie on four trials. Cookie sizes used: Training (T) trial: $1 \mathrm{~g}$; trial 1: $50 \mathrm{mg}$; trial 2: $150 \mathrm{mg}$; trial 3: $50 \mathrm{mg}$. Pan $\times 1^{-/-}$mice took significantly longer on trial 3 to retrieve the cookie $\left(p=0.02, \mathrm{~N}_{\operatorname{Pan} \times 1^{-/-}}=14, \mathrm{~N}_{\operatorname{Pan} \times 1^{+/+}}=15\right)$. (B) Velocity analysis showed a significantly higher mobility of Panx $1^{-/-}$mice. ${ }^{*} p<0.05$. Error bars indicate s.e.m.

$58 \mathrm{~s}$, Panx1 $\left.1^{-/-}=439 \pm 107 \mathrm{~s}, p=0.02\right)$. Further, they did not improve compared to the previous days (day 2) and training day (T) when conditions were easier (Figure 6A). This suggests that processing of olfactory information was not affected, as both animal cohorts did find the $50 \mathrm{mg}$ cookie on test day one at the same time, but the ability of the animals to learn the test was significantly altered. We also tracked the velocity of the animals and found that Panx1 $1^{-/-}$mice showed a significantly higher mobility $\left(\mathrm{Panxl}^{+/+}=4.7 \pm 0.3 \mathrm{~cm} / \mathrm{s}, \mathrm{Panx}^{-/-}=6.2 \pm 0.5 \mathrm{~cm} / \mathrm{s}\right.$, $p=0.02$ ) compared to Panx $1^{+/+}$mice (Figure 6B).

\section{DISCUSSION}

Our results show that Panx1 and Panx2 are expressed in the OE, with the expected lack of Panxl expression in Panx1-/mice. No compensatory regulation of Panx2 was observed. Insitu hybridizations of OE slices revealed that Panxl mRNA is expressed in OSNs, and to a lower extent in SCs and basal cells, which is in accordance to a recent study (Zhang et al., 2012). We further showed that the Panx1 protein is localized in axon bundles of OSNs. The role of Panxl channels in axon bundles is unclear. However, this localization and the apparent lack of Panx1 channels in the ciliary layer of the OE could explain why Panxl is not directly involved in the olfactory signal transduction and activation of OSNs, in which case a ciliary localization would be most likely. Stimulation with short, single odorant pulses, or testing of adaptation, did evoke similar responses in Panx1-/and Panx $1^{+/+}$mice in EOG recordings. The kinetics of the EOG responses, namely the rise and decay times, were similar in both mouse groups, indicating no major difference in signal amplification and termination mechanisms, further substantiated by IHC staining and qPCR data for major signal transduction proteins, which showed no significant changes in localization and steady state mRNA expression (Supplementary Figures 1,2), Behavioral testing was used to investigate the animals' capability to detect odorant cues. Since processing of olfactory information appeared unaffected, whereas the ability of the animals to learn the test was significantly altered, we conclude that learning and memory capabilities are impaired in Panx1 $1^{-/-}$animals (Prochnow et al., 2012).

Extracellular ATP is known to modulate olfactory responsiveness and influence proliferation and neuronal differentiation (Hassenklöver et al., 2009; Jia et al., 2009, 2011; Gao et al., 2010). It was tempting to hypothesize that the ablation of Panx1, a major release channel for ATP (Locovei et al., 2006; Qiu and Dahl, 2009; Dahl and Keane, 2012), alters OE function, either by influencing neuronal turnover in the OE, or being directly involved in the olfactory signal transduction/adaptation. Therefore, we quantified extracellular ATP concentrations ex vivo in the OEs of unchallenged Panx $1^{+/+}$and Panx $1^{-/-}$animals, and after exposure to $\mathrm{H} 100$ and potassium gluconate. The latter has previously been shown to open Panxl channels in vitro (Silverman et al., 2009). Application of potassium gluconate revealed significant changes between wild type and Panx1-/animals, with ablation of Panx1 channels causing a significant reduction of potassium gluconate stimulated ATP release. The observed reduction is consistent with two previous studies. Similar to our results, extracellular ATP deriving from isolated erythrocytes (Qiu et al., 2011), or lumbar and sacral spinal cord slices (Lutz et al., 2013) were virtually identical in Panx1 $1^{+/+}$ and Panx $1^{-/-}$mice. In contrast to human erythrocytes, where Panxl channel inhibitors almost completely abolish ATP release, a substantial release remained in mouse erythrocytes even after probenecid treatment and the reduction in ATP release upon potassium stimulation was less than 50\% (Qiu et al., 2011). Taken together, these findings are remarkable consistent in two independently generated Panx1KO models, supporting the role of Panx1 in ATP release and pointing at the existence of alternative ATP release pathways.

A challenge in future investigations will be to dissect the alternative ATP release pathways. Candidates are manifold and include vesicular release, connexin hemichannels, and ABC transporters, all present in the OE (Hayoz et al., 2012). In this study, we provide first evidence that LRRC8 channels, recently described as proteins with structural similarities to connexins and pannexins (Abascal and Zardoya, 2012), are expressed in the OE (Supplementary Figure 3). However, it remains to be demonstrated whether these channels are capable of releasing ATP. It is worth noting that expression of CALHM1, another channel with structural similarities to pannexins and ATP release capability (Siebert et al., 2013; Taruno et al., 2013) was not detected in the OE (unpublished data). Finally, compensatory regulation of connexins or pannexin proteins (Lohman and Isakson, 2014; Penuela et al., 2014) needs to be investigated to clarify synergistic or competing mechanisms of ATP efflux without Panx1 channels.

Arguably, the results presented in this study strongly advocate for a detailed analysis of ATP release mechanisms in the absence of Panx1. As shown, the characterization of Panx1 $1^{-/-}$mice does not support a prominent role of Panx 1 channels in olfaction, and it was concluded that the behavioral abnormalities observed in Panx $1^{-/-}$mice derive from alterations of integrating neuronal processes, as observed in the hippocampus. In summary, our findings highlight the role of Panx1 as a major ATP release site operating in the $\mathrm{OE}$ alongside alternative pathways.

\section{AUTHOR CONTRIBUTIONS}

Stefan Kurtenbach and Georg Zoidl planned the project. Stefan Kurtenbach, Paige Whyte-Fagundes, Lian Gelis, Christiane Zoidl performed experiments. Stefan Kurtenbach, Georg Zoidl wrote 
the manuscript. Sarah Kurtenbach, Valery I. Shestopalov, and Hanns Hatt helped with data evaluation, interpretation, and manuscript preparation. Valery I. Shestopalov generated the mouse model.

\section{ACKNOWLEDGMENTS}

We thank Drs. Silvia Penuela and Dale Laird (Western University, ON, Canada) for kindly providing the anti-Panx1 antibody. NIH grant EY021517 and Russian Federal Special Program Grant 2012-1.5-12-000-1002-018 (Valery I. Shestopalov). The International Max Planck Research School (IMPRS). NSERC-DG (Georg Zoidl). The Research School and International Graduate School of Neuroscience (IGSN), Ruhr University Bochum, Germany.

\section{SUPPLEMENTARY MATERIAL}

The Supplementary Material for this article can be found online at: http://www.frontiersin.org/journal/10.3389/fncel. 2014.00266/abstract

\section{REFERENCES}

Abascal, F., and Zardoya, R. (2012). LRRC8 proteins share a common ancestor with pannexins, and may form hexameric channels involved in cell-cell communication. Bioessays 34, 551-560. doi: 10.1002/bies.201100173

Azorin, N., Raoux, M., Rodat-Despoix, L., Merrot, T., Delmas, P., and Crest, M. (2011). ATP signalling is crucial for the response of human keratinocytes to mechanical stimulation by hypo-osmotic shock. Exp. Dermatol. 20, 401-407. doi: 10.1111/j.1600-0625.2010.01219.x

Bao, L., Locovei, S., and Dahl, G. (2004). Pannexin membrane channels are mechanosensitive conduits for ATP. FEBS Lett. 572, 65-68. doi: 10.1016/j.febslet.2004.07.009

Baranova, A., Ivanov, D., Petrash, N., Pestova, A., Skoblov, M., Kelmanson, I., et al. (2004). The mammalian pannexin family is homologous to the invertebrate innexin gap junction proteins. Genomics 83, 706-716. doi: 10.1016/j.ygeno.2003.09.025

Bargiotas, P., Krenz, A., Hormuzdi, S. G., Ridder, D. A., Herb, A., Barakat, W., et al. (2011). Pannexins in ischemia-induced neurodegeneration. Proc. Natl. Acad. Sci. U.S.A. 108, 20772-20777. doi: 10.1073/pnas.1018262108

Bargiotas, P., Krenz, A., Monyer, H., and Schwaninger, M. (2012). Functional outcome of pannexin-deficient mice after cerebral ischemia. Channels (Austin) 6, 453-456. doi: 10.4161/chan.22315

Bobbin, R. P., and Thompson, M. H. (1978). Effects of putative transmitters on afferent cochlear transmission. Ann. Otol. Rhinol. Laryngol. 87, 185-190.

Brunert, D., Kurtenbach, S., Isik, S., Benecke, H., Hatt, H., and Wetzel, C. H. (2009). Odorant-dependent generation of nitric oxide in mammalian olfactory sensory neurons. PLoS ONE 4:e5499. doi: 10.1371/journal.pone.0005499

Bruzzone, R., Hormuzdi, S. G., Barbe, M. T., Herb, A., and Monyer, H. (2003). Pannexins, a family of gap junction proteins expressed in brain. Proc. Natl. Acad. Sci. U.S.A. 100, 13644-13649. doi: 10.1073/pnas.2233464100

Dahl, G., and Keane, R. W. (2012). Pannexin: from discovery to bedside in $11 \pm 4$ years? Brain Res. 1487, 150-159. doi: 10.1016/j.brainres.2012.04.058

Dvoriantchikova, G., Ivanov, D., Barakat, D., Grinberg, A., Wen, R., Slepak, V. Z., et al. (2012). Genetic ablation of Pannexin1 protects retinal neurons from ischemic injury. PLoS ONE 7:e31991. doi: 10.1371/journal.pone.0031991

Dvoriantchikova, G., Ivanov, D., Panchin, Y., and Shestopalov, V. I. (2006). Expression of pannexin family of proteins in the retina. FEBS Lett. 580, 2178-2182. doi: 10.1016/j.febslet.2006.03.026

Finger, T. E., Danilova, V., Barrows, J., Bartel, D. L., Vigers, A. J., Stone, L., et al. (2005). ATP signaling is crucial for communication from taste buds to gustatory nerves. Science 310, 1495-1499. doi: 10.1126/science.1118435

Gao, L., Cao, L., Qiu, Y., Su, Z., Burnstock, G., Xiang, Z., et al. (2010). Blocking P2X receptors can inhibit the injury-induced proliferation of olfactory epithelium progenitor cells in adult mouse. Int. J. Pediatr. Otorhinolaryngol. 74, 747-751. doi: 10.1016/j.ijporl.2010.03.030
Gründken, C., Hanske, J., Wengel, S., Reuter, W., Abdulazim, A., Shestopalov, V. I., et al. (2011). Unified patch clamp protocol for the characterization of Pannexin 1 channels in isolated cells and acute brain slices. J. Neurosci. Methods 15, 15-25. doi: 10.1016/j.jneumeth.2011.04.016

Hanstein, R., Negoro, H., Patel, N. K., Charollais, A., Meda, P., Spray, D. C., et al. (2013). Promises and pitfalls of a Pannexin 1 transgenic mouse line. Front. Pharmacol. 4:61. doi: 10.3389/fphar.2013.00061

Hassenklöver, T., Schwartz, P., Schild, D., and Manzini, I. (2009). Purinergic signaling regulates cell proliferation of olfactory epithelium progenitors. Stem Cells 27, 2022-2031. doi: 10.1002/stem.126

Hayoz, S., Jia, C., and Cosgrove Hegg, C. (2012). Mechanisms of constitutive and ATP-evoked ATP release in neonatal mouse olfactory epithelium. BMC Neurosci. 13:53. doi: 10.1186/1471-2202-13-53

Hegg, C. C., Greenwood, D., Huang, W., Han, P., and Lucero, M. T. (2003). Activation of purinergic receptor subtypes modulates odor sensitivity. J. Neurosci. 23, 8291-8301.

Huang, Y.-J., Maruyama, Y., Dvoryanchikov, G., Pereira, E., Chaudhari, N., and Roper, S. D. (2007). The role of pannexin 1 hemichannels in ATP release and cell-cell communication in mouse taste buds. Proc. Natl. Acad. Sci. U.S.A. 104, 6436-6441. doi: 10.1073/pnas.0611280104

Jia, C., Doherty, J. P., Crudgington, S., and Hegg, C. C. (2009). Activation of purinergic receptors induces proliferation and neuronal differentiation in Swiss Webster mouse olfactory epithelium. Neuroscience 163, 120-128. doi: 10.1016/j.neuroscience.2009.06.040

Jia, C., Sangsiri, S., Belock, B., Iqbal, T. R., Pestka, J. J., and Hegg, C. C. (2011). ATP mediates neuroprotective and neuroproliferative effects in mouse olfactory epithelium following exposure to satratoxin $\mathrm{G}$ in vitro and in vivo. Toxicol. Sci. 124, 169-178. doi: 10.1093/toxsci/kfr213

Kranz, K., Dorgau, B., Pottek, M., Herrling, R., Schultz, K., Bolte, P., et al. (2013). Expression of Pannexin 1 in the outer plexiform layer of the mouse retina and physiological impact of its knockout. J. Comp. Neurol. 521, 1119-1135. doi: $10.1002 / \mathrm{cne} .23223$

Larsson, M. C., Domingos, A. I., Jones, W. D., Chiappe, M. E., Amrein, H., and Vosshall, L. B. (2004). Or83b encodes a broadly expressed odorant receptor essential for Drosophila olfaction. Neuron 43, 703-714. doi: 10.1016/j.neuron.2004.08.019

Locovei, S., Wang, J., and Dahl, G. (2006). Activation of pannexin 1 channels by ATP through P2Y receptors and by cytoplasmic calcium. FEBS Lett. 580, 239-244. doi: 10.1016/j.febslet.2005.12.004

Lohman, A. W., and Isakson, B. E. (2014). Differentiating connexin hemichannels and pannexin channels in cellular ATP release. FEBS Lett. 588, 1379-1388. doi: 10.1016/j.febslet.2014.02.004

Lutz, S. E., Gonzalez-Fernandez, E., Ventura, J. C., Perez-Samartin, A., Tarassishin, L., Negoro, H., et al. (2013). Contribution of pannexinl to experimental autoimmune encephalomyelitis. PLoS ONE 8:e66657. doi: 10.1371/journal.pone.0066657

Muñoz, D. J., Thorne, P. R., Housley, G. D., Billett, T. E., and Battersby, J. M. (1995). Extracellular adenosine $5^{\prime}$-triphosphate (ATP) in the endolymphatic compartment influences cochlear function. Hear. Res. 90, 106-118.

Pelegrin, P., and Surprenant, A. (2006). Pannexin-1 mediates large pore formation and interleukin-1beta release by the ATP-gated P2X7 receptor. EMBO J. 25, 5071-5082. doi: 10.1038/sj.emboj.7601378

Penuela, S., Bhalla, R., Gong, X.-Q., Cowan, K. N., Celetti, S. J., Cowan, B. J., et al. (2007). Pannexin 1 and pannexin 3 are glycoproteins that exhibit many distinct characteristics from the connexin family of gap junction proteins. J. Cell Sci. 120, 3772-3783. doi: 10.1242/jcs.009514

Penuela, S., Kelly, J. J., Churko, J. M., Barr, K. J., Berger, A. C., and Laird, D. W. (2014). Panxl regulates cellular properties of keratinocytes and dermal fibroblasts in skin development and wound healing. J. Invest. Dermatol. 134, 2026-2035. doi: 10.1038/jid.2014.86

Pfaffl, M. W., Horgan, G. W., and Dempfle, L. (2002). Relative expression software tool (REST) for group-wise comparison and statistical analysis of relative expression results in real-time PCR. Nucleic Acids Res. 30:e36. doi: 10.1093/nar/30.9.e36

Prochnow, N., Abdulazim, A., Kurtenbach, S., Wildförster, V., Dvoriantchikova, G., Hanske, J., et al. (2012). Pannexin 1 stabilizes synaptic plasticity and is needed for learning. PLoS ONE 7:e51767. doi: 10.1371/journal.pone.0051767

Prochnow, N., Hoffmann, S., Dermietzel, R., and Zoidl, G. (2009). Replacement of a single cysteine in the fourth transmembrane region of zebrafish pannexin 
1 alters hemichannel gating behavior. Exp. Brain Res. 199, 255-264. doi: 10.1007/s00221-009-1957-4

Qiu, F., and Dahl, G. (2009). A permeant regulating its permeation pore: inhibition of pannexin 1 channels by ATP. Am. J. Physiol. Cell Physiol. 296, C250-C255. doi: 10.1152/ajpcell.00433.2008

Qiu, F., Wang, J., Spray, D. C., Scemes, E., and Dahl, G. (2011). Two non-vesicular ATP release pathways in the mouse erythrocyte membrane. FEBS Lett. 585, 3430-3435. doi: 10.1016/j.febslet.2011.09.033

Ray, A., Zoidl, G., Weickert, S., Wahle, P., and Dermietzel, R. (2005). Site-specific and developmental expression of pannexin 1 in the mouse nervous system. Eur. J. Neurosci. 21, 3277-3290. doi: 10.1111/j.1460-9568.2005.04139.x

Ray, A., Zoidl, G., Wahle, P., and Dermietzel, R. (2006). Pannexin expression in the cerebellum. Cerebellum 5, 189-192. doi: 10.1080/147342205005 30082

Siebert, A. P., Ma, Z., Grevet, J. D., Demuro, A., Parker, I., and Foskett, J. K. (2013). Structural and functional similarities of calcium homeostasis modulator 1 (CALHM1) ion channel with connexins, pannexins, and innexins. J. Biol. Chem. 288, 6140-6153. doi: 10.1074/jbc.M112.409789

Silverman, W. R., de Rivero Vaccari, J. P., Locovei, S., Qiu, F., Carlsson, S. K., Scemes, E., et al. (2009). The pannexin 1 channel activates the inflammasome in neurons and astrocytes. J. Biol. Chem. 284, 18143-18151. doi: 10.1074/jbc.M109.004804

Sosinsky, G. E., Boassa, D., Dermietzel, R., Duffy, H. S., Laird, D. W., MacVicar, B., et al. (2011). Pannexin channels are not gap junction hemichannels. Channels 5, 193-197. doi: 10.4161/chan.5.3.15765

Taruno, A., Vingtdeux, V., Ohmoto, M., Ma, Z., Dvoryanchikov, G., Li, A., et al. (2013). CALHM1 ion channel mediates purinergic neurotransmission of sweet, bitter and umami tastes. Nature 495, 223-226. doi: 10.1038/ nature 11906

Vessey, K. A., and Fletcher, E. L. (2012). Rod and cone pathway signalling is altered in the P2X7 receptor knock out mouse. PLoS ONE 7:e29990. doi: 10.1371/journal.pone.0029990

Vick, J. S., and Delay, R. J. (2012). ATP excites mouse vomeronasal sensory neurons through activation of P2X receptors. Neuroscience 220, 341-350. doi: 10.1016/j. neuroscience.2012.06.004

Vroman, R., Klaassen, L. J., Howlett, M. H. C., Cenedese, V., Klooster, J., Sjoerdsma, T., et al. (2014). Extracellular ATP hydrolysis inhibits synaptic transmission by increasing ph buffering in the synaptic cleft. PLoS Biol. 12:e1001864. doi: 10.1371/journal.pbio.1001864
Wang, X.-H., Streeter, M., Liu, Y.-P., and Zhao, H.-B. (2009). Identification and characterization of pannexin expression in the mammalian cochlea. J. Comp. Neurol. 512, 336-346. doi: 10.1002/cne.21898

Wetzel, C. H., Oles, M., Wellerdieck, C., Kuczkowiak, M., Gisselmann, G., and Hatt, H. (1999). Specificity and sensitivity of a human olfactory receptor functionally expressed in human embryonic kidney 293 cells and Xenopus laevis oocytes. J. Neurosci. 19, 7426-7433.

Wurm, A., Pannicke, T., Iandiev, I., Francke, M., Hollborn, M., Wiedemann, P., et al. (2011). Purinergic signaling involved in Müller cell function in the mammalian retina. Prog. Retin. Eye Res. 30, 324-342. doi: 10.1016/j.preteyeres.2011. 06.001

Zhang, H., Chen, Y., and Zhang, C. (2012). Patterns of heterogeneous expression of pannexin 1 and pannexin 2 transcripts in the olfactory epithelium and olfactory bulb. J. Mol. Histol. 43, 651-660. doi: 10.1007/s10735-012-9443-x

Zhu, Y., and Zhao, H.-B. (2012). ATP activates P2X receptors to mediate gap junctional coupling in the cochlea. Biochem. Biophys. Res. Commun. 426, 528-532. doi: 10.1016/j.bbrc.2012.08.119

Zoidl, G., Kremer, M., Zoidl, C., Bunse, S., and Dermietzel, R. (2008). Molecular diversity of connexin and pannexin genes in the retina of the zebrafish Danio rerio. Cell Commun. Adhes. 15, 169-183. doi: 10.1080/15419060802014081

Conflict of Interest Statement: The authors declare that the research was conducted in the absence of any commercial or financial relationships that could be construed as a potential conflict of interest.

Received: 27 May 2014; accepted: 18 August 2014; published online: 12 September 2014.

Citation: Kurtenbach S, Whyte-Fagundes P, Gelis L, Kurtenbach S, Brazil É, Zoidl $C$, Hatt H, Shestopalov VI and Zoidl G (2014) Investigation of olfactory function in a Panx1 knock out mouse model. Front. Cell. Neurosci. 8:266. doi: 10.3389/fncel. 2014.00266

This article was submitted to the journal Frontiers in Cellular Neuroscience.

Copyright (c) 2014 Kurtenbach, Whyte-Fagundes, Gelis, Kurtenbach, Brazil, Zoidl, Hatt, Shestopalov and Zoidl. This is an open-access article distributed under the terms of the Creative Commons Attribution License (CC BY). The use, distribution or reproduction in other forums is permitted, provided the original author(s) or licensor are credited and that the original publication in this journal is cited, in accordance with accepted academic practice. No use, distribution or reproduction is permitted which does not comply with these terms. 